\title{
WASTE MANAGEMENT WITHIN CONTEXT OF URBAN SUSTAINABLE DEVELOPMENT: BIBLIOMETRIC ANALYSIS
}

\author{
Regina Veckalne, Tatjana Tambovceva \\ Riga Technical University, Latvia \\ regina_gaynulina@mail.ru, tatjana.tambovceva@rtu.lv
}

\begin{abstract}
Since the adoption of the 2030 Agenda for Sustainable Development by the United Nations, many were given hope in today's world, which is despite being technically advanced still remains troublesome by leaving the majority of the population desperate and helpless. This Agenda focuses on the 17 Sustainability Goals that cover 169 various targets that are believed to shift the world onto a more sustainable and resilient path. The development of an effective and efficient waste management system is an increasingly important step towards the 17 goals. Cities are known to be the motor of economic activities; however, they are also the hubs of excessive waste generation. Despite the fact that cities take up only 2 percent of the global space, they use over 75 percent of resources, while generating over 70 percent of all the global waste. Waste generation is being linked with water consumption and pollution, dwindling of natural resources, and as a consequence negative impact on the environment. The management of municipal waste that is generated in households is commonly accepted to be largely ineffective. Thus, the research draws attention to the problem of municipal waste management in the context of sustainable urban development. The purpose of this study is to perform a bibliometric analysis of the scientific articles on waste management. To do so, the authors selected 168 papers published between 1995 and 2020. Out of the examined articles, 161 items divided into 6 clusters were detected. Although waste management is known to have a significant influence on the sustainability level, the analysis indicated that this theme has not been studied sufficiently enough. Additionally, many scholars only consider it to be an environmental topic, while in practice it also affects social and economic aspects.
\end{abstract}

Keywords: sustainable development, urban sustainability, waste management.

\section{Introduction}

The concept of "utility", introduced by Jeremy Bentham - English philosopher and sociologist, and further developed by logician and economist U.S. Jevons, characterizes objective results of some actions, effectiveness, and efficiency of economic and managerial decisions as well as qualitative comparison of costs and efforts employed while utilizing scarce resources [1]. There are two concepts: utility and marginal utility present in the economic theory. Additionally, within the field of social economics the concept of social utility, which highlights ecological utility as a specific type of economic good, is being developed [2]. It is suggested to consider utility as a complex of functional and ecological utility.

If we look at waste from the utility point of view, then it is clear that along with low functional utility it has negative ecological utility, which decreases or even nullifies its "general" utility. Meanwhile, in the process of waste utilization, taking into consideration state-of-art technological advancements, economic goods that provide functional utility can be produced, whilst an effective waste management system increases the ecological utility of the acquired good [3]. Despite the obvious benefit and potential effectiveness of waste management, as well as constant development of technologies aimed at extraction of advantages from the recycling process, at present waste management in many countries only includes reduction of waste, recycling, landfilling, or burning.

Waste management is a socio-economic element of the development theory, which implies long term investment into processes of waste collection, sorting, transportation, recycling, and utilization, whilst the creation of infrastructure, as well as social and ethical behavioural norms [4]. Since this process implicit in a complex integrative economic structure, it is argued that an effective managerial economic model of regional waste management structure should be built on the combination of market and administrative mechanisms that will include the formation of a necessary level of environmental education and societal awareness.

The concept of sustainable development is closely related to waste management, because not only does it affect the ecology, but also the social aspect. Since the number of city dwellers is continuously growing, and with them grows the consumption, focus on waste management can positively influence both urban communities and the ecosystem [5]. Waste generation is intrinsic to urbanization; thus, this 
article draws attention to the problem of waste management in urban areas in the context of urban development.

This research draws attention to the problem of municipal waste management in the context of sustainable urban development, as despite the fact that this topic is increasingly important, it is believed that it is not researched well enough up until today. The purpose of this study is to perform bibliometric analysis of the scientific articles on waste management and indicate the trends of publications in this field of research.

\section{Literature review}

With rapid urbanization, the problem of waste management becomes increasingly important. While cities are hubs of economic and social activities, the functioning of every city generates waste, and considering that the majority of the global population now lives in urban areas the amount of generated in cities waste becomes unbearable. According to various literature, sources of waste can be classified as municipal and industrial. As demonstrated on the Figure 1 the amount of municipal waste, produced by households, naturally continues to grow and is expected to grow with the rise of population.

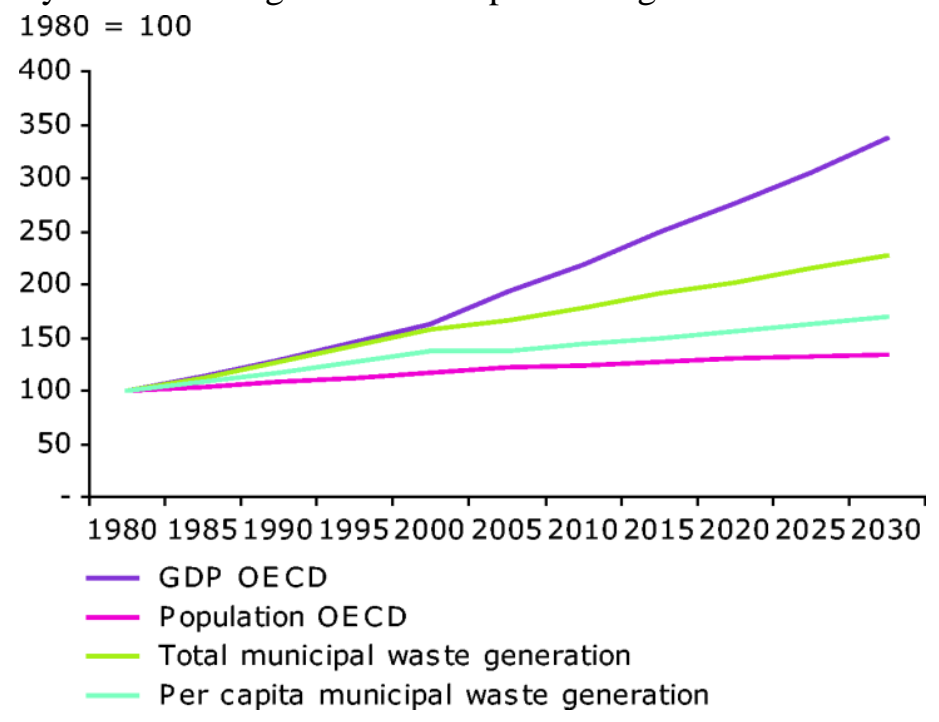

Fig. 1. OECD country municipal waste generation, 1980-2030 [6]

Using Google Ngram Viewer, it was established that the first interest in sustainable waste management concept appeared in the late 1930s lasting until approximately 1945, then, however, there was not much published in this field up until the mid-1980s, where we can observe a significant increase in the number of publications. Reaching its peak in the 2000s, the popularity of this topic was followed by an abrupt decline approaching the 2010s and recovering despite some minor fluctuations in the late 2010s (Figure 2).

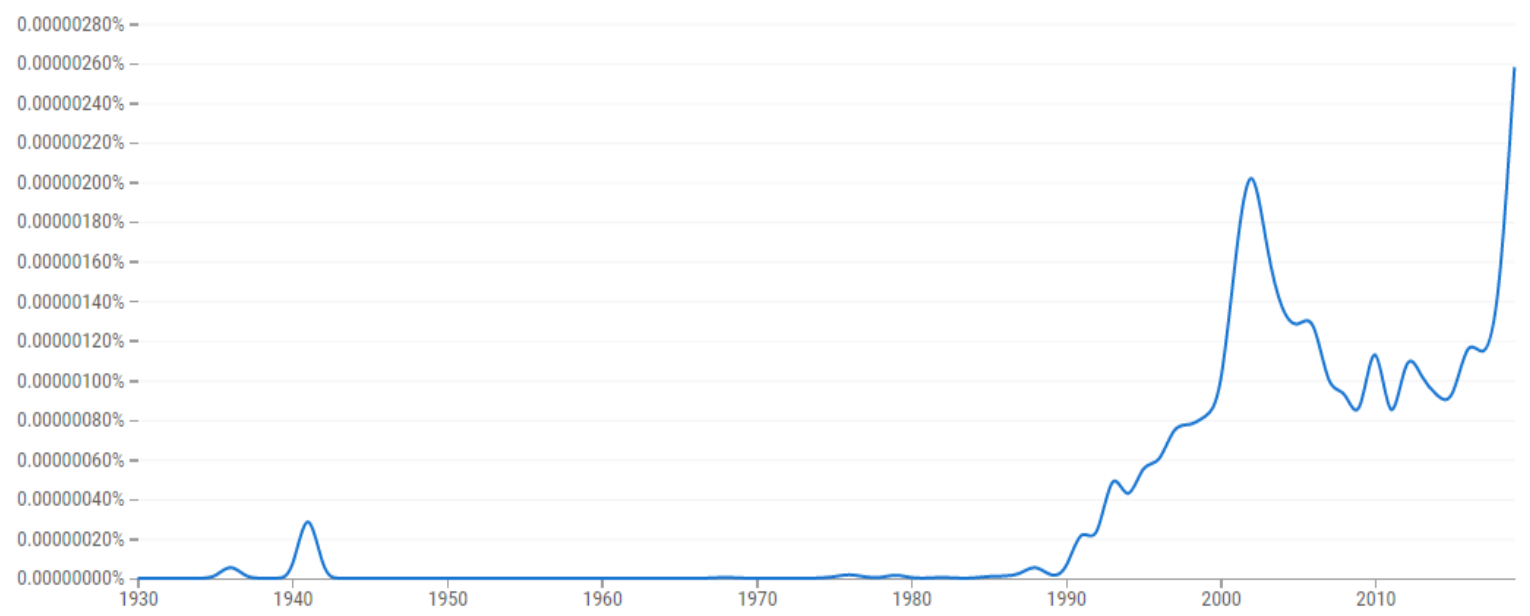

Fig. 2. Frequency of using the term "sustainable waste management" [7] 
A vital part of waste management is the creation of waste management systems (WMSs). WMSs can be defined as organized programs and facilities that are built for waste disposal, recycling, reuse, composting, and incineration. When sustainable WMS is being planned, it is of high importance to account for environmental, social, and economic aspects [8]. While environmental aspects are often considered, many ignore the economic and social sides. Municipal solid waste management systems have been studied by many authors. Many of them stress the importance of system analysis tools to support decision-making processes [8-10]. According to Chang et al. [11], there are two different types of such tools, namely system assessment (e.g., material flow analysis or life cycle assessment) and system engineering models, such as cost-benefit analyses. Meanwhile, there are also mathematical models of WMSs, which are oftentimes based on Non-Linear Programming, Linear Programming, and Mixed Integer Linear Programming [10]. Such models can provide an accurate description of the existing problem, however, lack the ability to help solve and comprehend decision making.

It is believed that environmental awareness of entrepreneurs and citizens may help reduce the impact of waste on the environment. One of the concepts driving society to reduce waste generation is the "zero waste" approach [12]. If rules governing the municipal waste management structures are realized, we can extend this concept to the creation of zero-waste cities, key features of which are demonstrated in Figure 3.

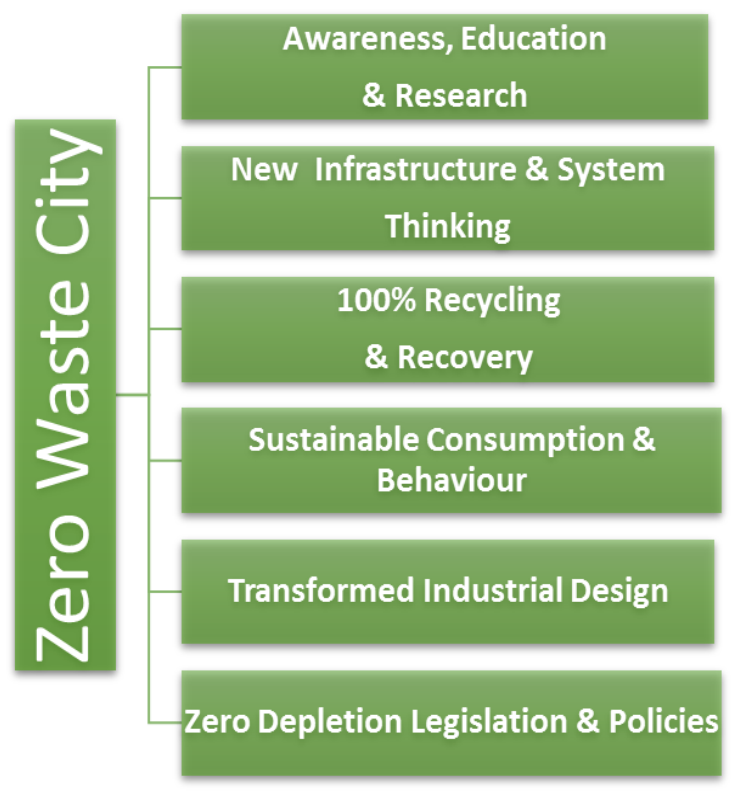

Fig. 3. Zero waste city features [12]

In many cities, especially in developing countries, the environment together with the health of citizens is degraded due to inefficient waste management systems, which make it an important factor of urban sustainability [13].

The most waste ends up in a landfill that is difficult to find, causing large waste mountains to be aroused in cities' neighbourhoods. In addition to that, landfilling is a very costly procedure, that is generally socially unaccepted and requires meeting strict legal and administrative requirements. Waste in landfills produces methane, one of the greenhouse gases, which makes it very hazardous for both people and the planet. Thus, waste recycle and recovery is desired whenever waste prevention is not possible [14]. Unlike industrial, municipal waste can be recycled at a relatively low cost and energy consumption. Meanwhile, the socio-economic benefits of such procedures can be seen as profits for the community as well as businesses, as waste management systems usually consist of multiple waste collection centres and disposal plants. Miyata et al [15] worked out a relationship between the municipal waste, city expenditure, and economic level, which is expressed as follows: Municipal Waste $=\mathrm{f}$ (economic level, city expenditure, population). It was concluded, that public investment was a necessary tool in the implementation of sustainable development in cities. 


\section{Materials and methods}

The data collection for this paper was conducted as follows. First of all, we searched for the keywords "sustainable development", "waste management", "waste management systems" and "sustainability factors" in the Scopus database. It resulted in 168 papers published from 1995 to 2020 in English. The bibliometric analysis was focused on the dynamics of publications, related subject areas, and countries with most publications. Additionally, the thematic scope of the selected publications was analysed via the VOSviewer tool, which enabled constructing a terminological map based on the cooccurrence of the searched keywords in the titles and abstracts of the investigated papers. It is worth noting that the results of the analysis produced in the VOSviewer are demonstrated on the thematic map while being formulated within clusters that show which of the keywords had been used in the same paper. The frequency of the usage of the keywords is visualized by the distance between bubbles, where the shorter the distance the higher the frequency. Last, but not the least, a higher citation rate, as well as higher keyword co-occurrence, as demonstrated by the size of the bubble.

The publications analysed in this study were only collected from the Scopus database and were written in English. It is worth extending this research to the analysis of publications from other databases in order to obtain a broader picture of the topic.

\section{Results}

After various scientific sources have been systematized and analyzed, it became clear that the topic of waste management in the context of urban sustainable development demands more attention. While there are studies that analyze various factors affecting waste management as such and WMSs $[12 ; 13$; $16 ; 17]$, not many scholars actually look at them as factors of urban sustainable development. In some papers $[8 ; 10 ; 18 ; 19]$ authors agree with the importance of waste management and WMSs in the context of sustainable development of cities, however, due to the essence of their research, they focus only on the ecological aspect. In this paper, we attempted to build the terminological map that is based on the coupling of the keywords mentioned in the titles and abstracts of the selected scientific articles. The Figure 4 demonstrates the frequency of keyword usage and link strength, developed by us using [20].

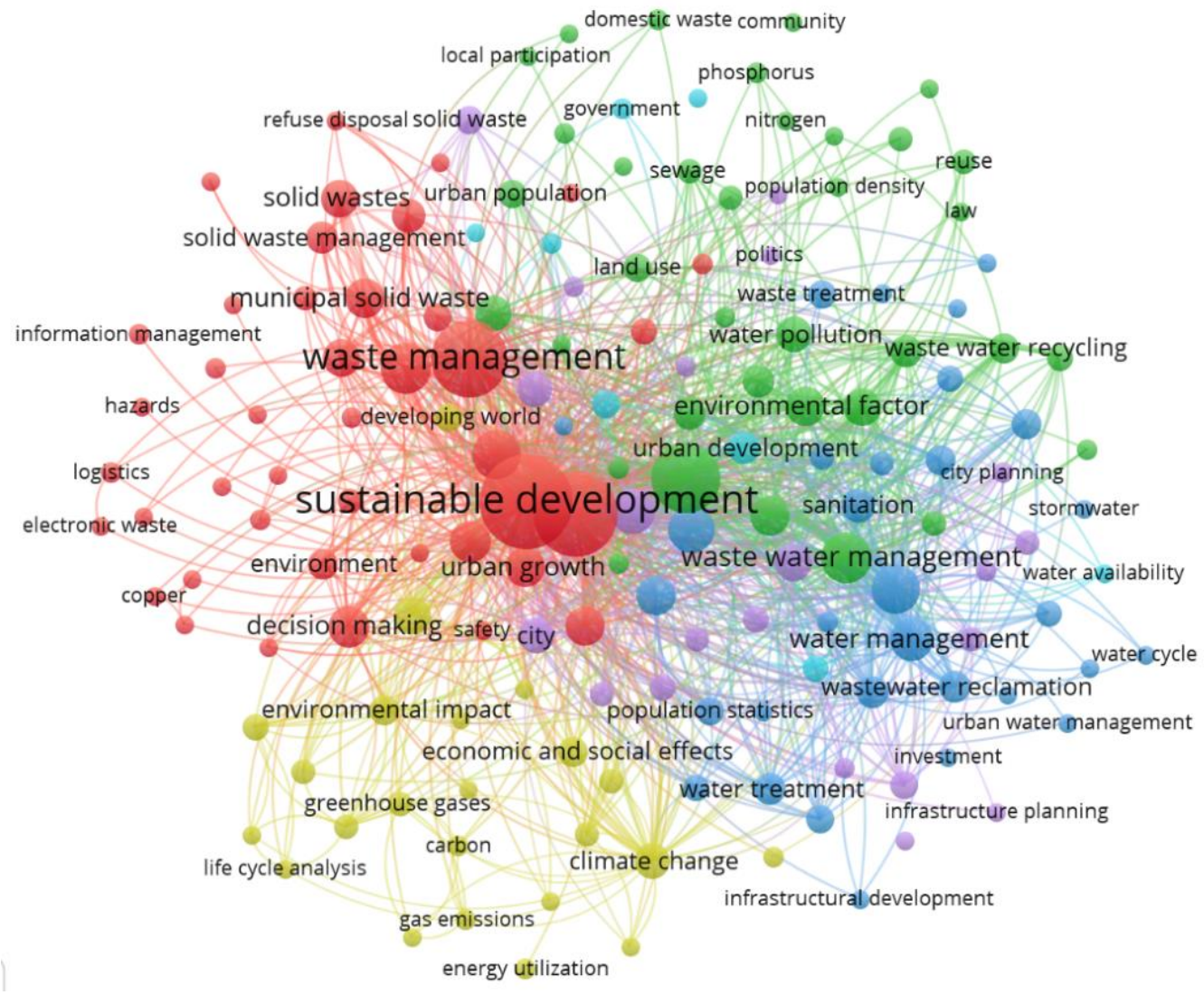

Fig. 4. Bibliometric coupling of the keywords in the investigated 
After the frequency was limited to three items, we have detected 161 items divided into 6 clusters. As it is seen on the map, the terms "sustainable development", "waste management", "urban development", "environmental factor", "water pollution/management", "urban growth", "decision making", "municipal solid waste" are among the most frequently used in the selected articles.

We then have taken a look at the Scopus analytical toolbar [21] to check the dynamics of the publications on the aforementioned topics. As it is demonstrated on Figure 5, we can observe that despite some notable fluctuation the overall tendency is positive.

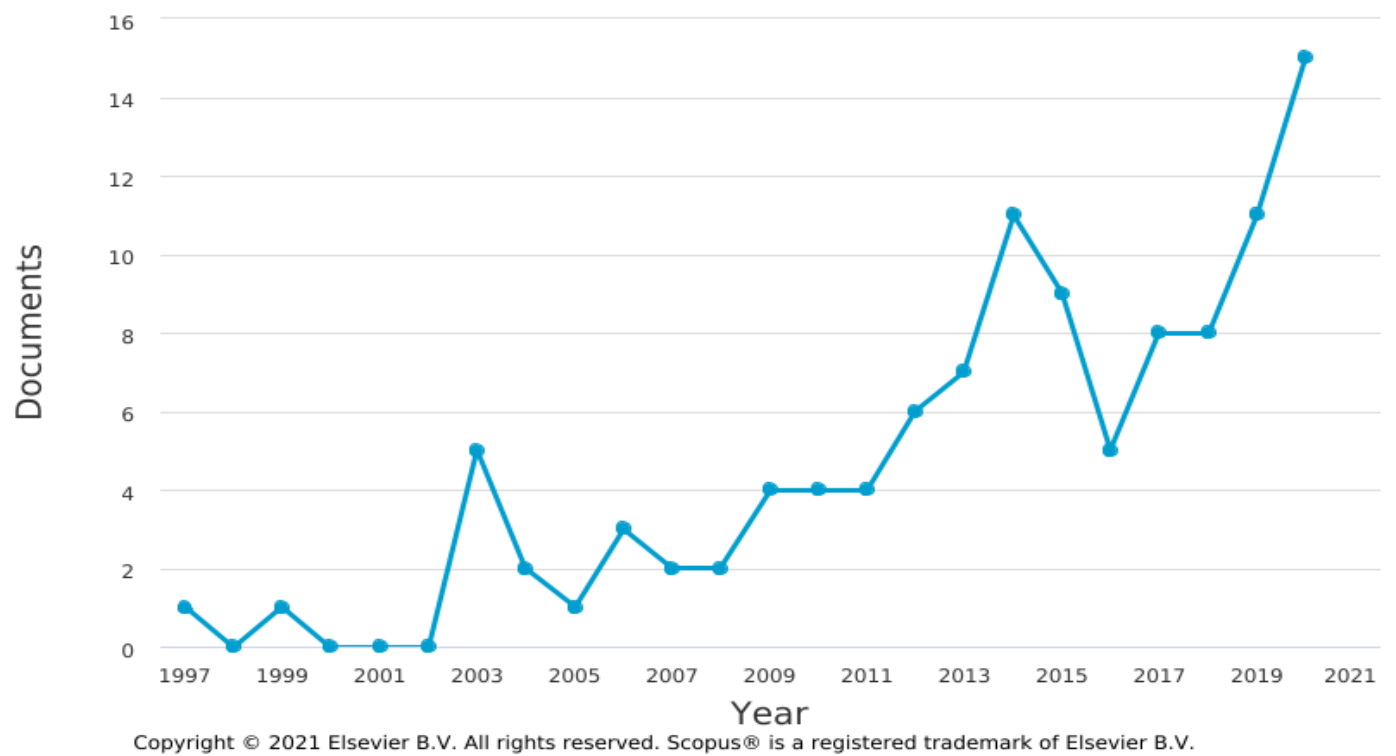

Fig. 5. Dynamics of publications between 1997 and 2021 (documents by year)

Additionally, it has been detected that Australia and China are the top countries in terms of publications on waste management related articles, followed by the United States, Sweden, and the Netherlands closing the top 5 list (Figure 6).

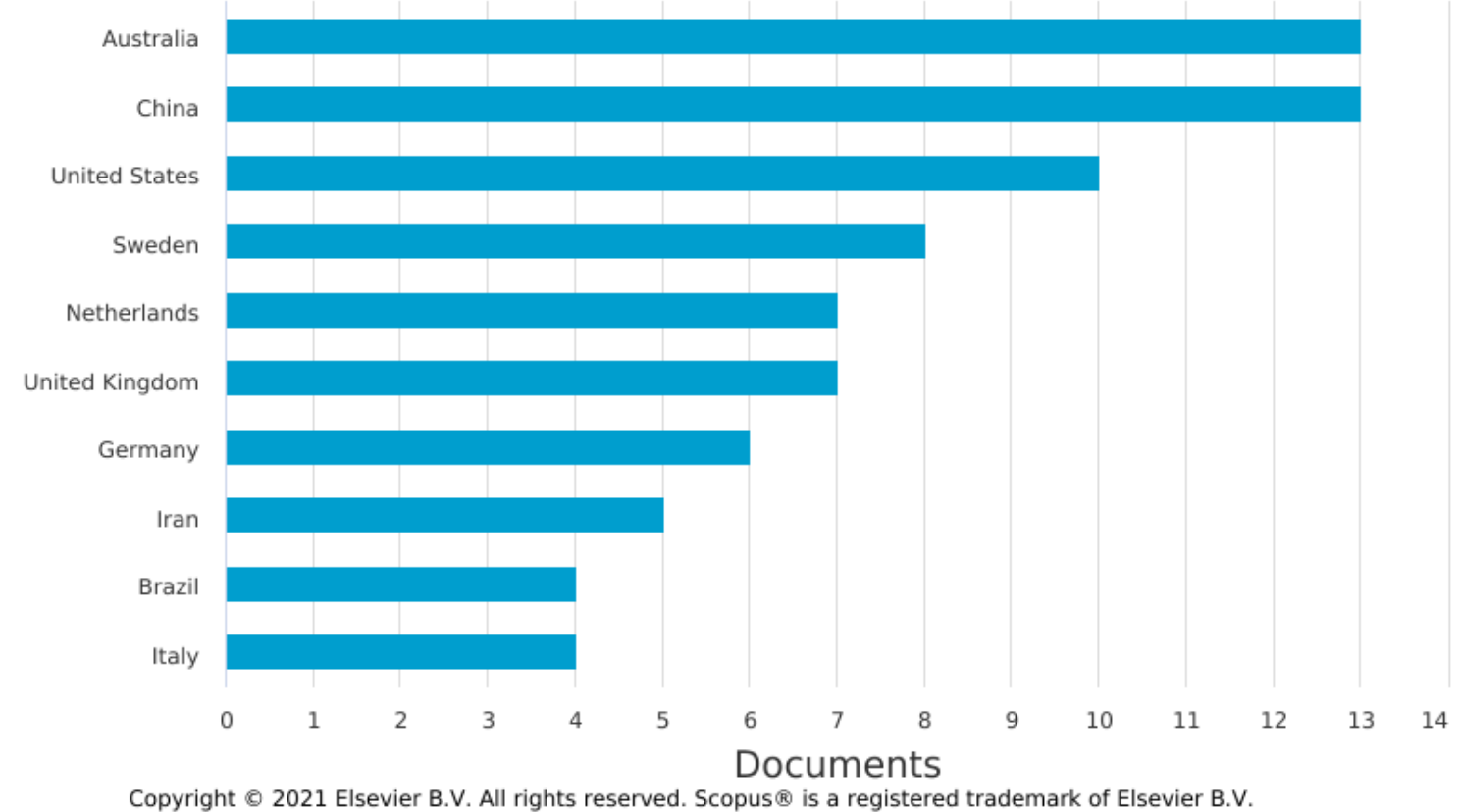

Fig. 6. Countries with the highest publication rate in Scopus 
As discussed by many scholars $[5 ; 9 ; 14 ; 19 ; 22]$, waste management is a multidisciplinary issue and therefore considered from various points of view, such as engineering, economics, business, social and environmental sciences, etc. As it has already been mentioned above, however, many see the challenge of adequate waste management as solely or most importantly an environment-related problem. While $47.8 \%$ of publications were associated with environmental sciences, $9.3 \%$ linked it to the field of engineering, $8.2 \%$ to the energy field and social sciences, and $4.9 \%$ and $3.8 \%$ relative to the areas of business, management, and economics.

\section{Conclusions}

Despite the obvious topicality of the theme of waste management and waste management systems, this subject has not been studied sufficiently enough up to these days. The analytical tools used for this article (VOSviewer and Scopus) enabled the production of bibliometric analysis of over 160 publications related to the topics, as well as examine the structure and dynamics of the selected publications. The obtained data demonstrated that in spite of some notable fluctuations the overall publications dynamics tendency is positive. It was established that Australia and China are the top producers of waste management related publications, followed by the United States, Sweden, the Netherlands, and the UK. The analysis produced in VOS viewer resulted in 161 items being divided into 6 clusters of research. The theoretical significance of this research lies in the analysis of the existing literature sources and the creation of maps that systematize and visualize the findings from the bibliometric analysis. It should be highlighted that too many waste management techniques and WMSs seem to be of high importance, when it comes to the environmental challenges, it is, however, a broader problem. Waste management practices have a significant impact on the sustainability level of development, as not only do they affect the environment, but also impact social aspects and economic indicators.

\section{References}

[1] Bentham, J., Bowring J. The Works of Jeremy Bentham. Edinburgh: W. Tait, 1843.

[2] Mesjasz-Lech A. Municipal Waste Management in Context of Sustainable Urban Development. Procedia - Social and Behavioral Sciences, vol. 151, 2014, pp. 244-256. DOI: $10.1016 /$ j.sbspro.2014.10.023

[3] Magazzino C., Mele M., Schneider N., Sarkodie S. A. Waste generation, wealth and GHG emissions from the waste sector: Is Denmark on the path towards circular economy? Science of the Total Environment, vol. 755, 2021, 142510. DOI: 10.1016/j.scitotenv.2020.142510

[4] Jansson $\AA$. Reaching for a sustainable, resilient urban future using the lens of ecosystem services. Ecological Economics, vol. 86, 2013, pp. 285-291. DOI: 10.1016/j.ecolecon.2012.06.013

[5] Bartolacci F., Paolini A., Quaranta A. G., Soverchia M. Assessing factors that influence waste management financial sustainability. Waste Management, vol. 79, 2018, pp. 571-579. DOI: 10.1016/j.wasman.2018.07.050

[6] European Environment Agency. [online] [31.03.2021]. Available at: https://www.eea.europa.eu/data-and-maps/figures/oecd-country-municipal-waste-generation1980-2030

[7] Ngram Viewer. [online] [13.03.2021]. Available at: https://books.google.com/ngrams

[8] Tascione V., Mosca R., Raggi A. A proposal of an economic optimization model for sustainable waste management. Journal of Cleaner Production, vol. 279, 2020, 123581. DOI: $10.1016 /$ j.jclepro.2020.123581

[9] Agyeiwaah E. The contribution of small accommodation enterprises to sustainable solid waste management. Journal of Hospitality and Tourism Management, vol. 44, 2020, pp. 1-9. DOI: $10.1016 /$ j.jhtm.2020.04.013

[10] Mamashli Z., Javadian N. Sustainable design modifications municipal solid waste management network and better optimization for risk reduction analyses. Journal of Cleaner Production, vol. 279, 2020, 123824. DOI: 10.1016/j.jclepro.2020.123824

[11] Chang NB., Qi C., Islam K., Hossain F. Comparisons between global warming potential and costbenefit criteria for optimal planning of a municipal solid waste management system. Journal of Cleaner Production, vol. 20, 2012, pp. 1-13. DOI: 10.1016/j.jclepro.2011.08.017 
[12]Zaman A.U., Lehmann S. The zero waste index: a performance measurement tool for waste management systems in a 'zero waste city'. Journal of Cleaner Production, vol. 50, 2013, pp. 123132. DOI: 10.1016/j.jclepro.2012.11.041

[13] Perteghella A., Gilioli G., Tudor T., Vaccari M. Utilizing an integrated assessment scheme for sustainable waste management in low and middle-income countries: Case studies from BosniaHerzegovina and Mozambique. Waste Management, vol. 113, 2020, pp. 176-185. DOI: 10.1016/j.wasman.2020.05.051

[14] McCormick K., Anderberg S., Coenen L., Neij L. Advancing sustainable urban transformation. Journal of Cleaner Production, vol. 50, 2013, pp. 1-11. DOI: 10.1016/j.jclepro.2013.01.003

[15] Miyata Y., Shibusawa H., Hossain N. An Economic Analysis of Municipal Solid Waste Management of Toyohashi City, Japan: Evidences from Environmental Kuznets Curve. Proceedings of 53rd ERSA Congress Regional Integration: Europe, the Mediterranean and the World economy. 27-31 August 2013, Palermo, Italy, paper 137. [online] [25.03.2021]. Available at: https://www.econstor.eu/bitstream/10419/123870/1/ERSA2013_00137.pdf

[16]Fehr A., Urushadze T., Zöller N., Knerr B., Ploeger A., \& Vogtmann H. Establishing a Sustainable Waste Management System in a Transitional Economic Context: Analysis of the Socio-Economic Dynamics. Sustainability, vol. 12, iss.9, 2020, pp. 3887. DOI: 10.3390/su12093887

[17] Mancini G. A, Luciano A., Bolzonella D., Fatone F., Viotti P., Fino D. Water-waste-energy nexus approach to bridge the sustainability gap in landfill-based waste management regions, Renewable and Sustainable Energy Reviews, vol. 137, 2021, 110441. DOI: 10.1016/j.rser.2020.110441

[18] Zheng H.W., Shen G.Q., Wang H. A review of recent studies on sustainable urban renewal. Habitat International, vol. 41, 2014, pp. 272-279. DOI: 10.1016/j.habitatint.2013.08.006

[19] Chen Y.-C. Effects of urbanization on municipal solid waste composition. Waste Management, vol. 79, 2018, pp. 828-836. DOI: 10.1016/j.wasman.2018.04.017

[20] VOSviewer [online] [15.03.2021]. Available at: https://www.vosviewer.com/

[21] Scopus. [online] [15.03.2021]. Available at: https://www.scopus.com

[22] Pearson L.J. In search of resilient and sustainable cities: Prefatory remarks. Ecological Economics, vol. 86, 2013, pp. 222-223. DOI: 10.1016/j.ecolecon.2012.11.020 